\title{
Galanteria e polidez. Sobre o Ivanhoe de Scott, e David Hume
}

Gallantry and politeness.

On Scott's Ivanhoe and David Hume

\section{Marcos Fonseca Ribeiro Balieiro \\ Universidade Federal de Sergipe}

\section{RESUMO}

Ainda que seja vista por alguns críticos como uma obra publicada apenas para servir como entretenimento, Ivanhoe, de Walter Scott, é um livro em que o autor se opóe ferrenhamente aos ideais de cavalaria, além de propor que a identidade nacional da Inglaterra teria se constituído a partir de uma síntese de maneiras originalmente opostas, a saber, as dos saxões e as dos conquistadores normandos. Tentar-se-á mostrar, ao longo deste artigo, que essa tese de Scott resulta de uma tomada de posição diante das considerações de David Hume acerca da relação entre a tradição medieval da cavalaria e a polidez moderna.

\section{PALAVRAS-CHAVE}

Ivanhoe, Walter Scott, David Hume Cavalaria, Galanteria, Polidez.

\section{ABSTRACT}

Even though it is seen by some critics as a work wich was published only as entertainment, Walter Scott's Ivanhoe is a book in which the author strongly opposes the ideals of chivalry, and states that the national identity of England is due to a synthesis between saxon and norman manners, which were originally opposite to each other. This paper aims at showing that Scott's thesis is, in a certain sense, a response to David Hume's considerations concerning the relation between medieval chivalry and modern politeness.

\section{KEY WORDS}

Ivanhoe, Walter Scott, David Hume, Chivalry, Gallantry, Politeness. 
Não foram poucos os críticos que, desde o século XIX, consideraram Ivanhoe, de Walter Scott, um romance que teria assegurado sua fama, por se constituir, antes de qualquer outra coisa, em um romance dedicado ao entretenimento infantil. Para esses críticos, o livro teria interesse por conta da "ingenuidade romântica" com que os ideais da cavalaria teriam sido retratados pelo autor, que teria cunhado uma história repleta de duelos e aventuras em que guerreiros destemidos enfrentam nobres que se dedicam a todo tipo de intrigas, usurpações e excessos. ${ }^{\mathrm{I}}$ Esse tipo de leitura parece, à primeira vista, compreensível. Trata-se, afinal, de uma história sobre um cavaleiro que, ao retornar da cruzada ${ }^{2}$, tendo realizado uma série de atos valorosos sob o estandarte de Ricardo Coração de Leão, enfrenta uma série de nobres maléficos, colaborando para que a Inglaterra permaneça sob o governo do rei legítimo. Além disso, como seria de se esperar em um bom romance de aventuras, os eventos que promovem o triunfo do herói sobre seus antagonistas o levam, também, a casar-se com seu verdadeiro amor.

Ainda assim, é bastante precipitado ler Ivanhoe como apenas um romance para garotos. Ora, não são poucos os aspectos em que a obra se distancia daquilo que seria de se esperar de um mero romance de aventuras. Mesmo um rápido olhar sobre as personagens principais basta para deixar esse ponto bastante claro. ${ }^{3}$ O protagonista Wilfred de Ivanhoe, longe de ser um herói perfeito, é apresentado como alguém que, apesar de dotado de bom senso, não é imune a peculiaridades e preconceitos, que o tornam bastante humano. Um bom exemplo é que, apesar de a personagem Rebecca ser caracterizada como excepcionalmente bela, altruísta e dotada de forte senso e grandeza de espírito, o herói passa a tratá-la com frieza após descobrir que ela é judia - o que ocorre, vale observar, justamente no momento em que ela se encarrega dos cuidados que possibilitarão uma cura mais rápida ao grave ferimento do protagonista. A heroína Rowena, por sua vez, é descrita

I Em artigo intitulado "The Anti-Romantic in Ivanhoe", Joseph Duncan, crítico dessa posição, menciona uma série de críticos literários que teriam optado por ela, tais como Herbert Grieson, Una Pope-Hennessy e Walter Bagehot. Este último, por exemplo, afirmou que Ivanhoe seria endereçado "àquele tipo de imaginação típica dos garotos que idolatram a sociedade medieval como sendo o "tempo dos duelos" (that kind of boyish fancy which idolizes medieval society as "the fighting time") (Duncan I955, p. 293).

2 Trata-se da Terceira Cruzada, ocorrida entre II89 e II92. Ainda que não tenha sido bemsucedida em retomar Jerusalém, tendo Ricardo I proposto uma trégua a Saladino por conta da exaustão das tropas, a expedição conseguiu reconquistar localidades importantes, revertendo muitas vitórias anteriores dos maometanos.

3 Utilizamos aqui a edição de 2005 da Barnes \& Noble, com introdução e notas de Gillen D’Arcy Wood (Scott 2005). 
meramente como alguém que possui grande beleza, e um temperamento que, apesar de naturalmente dócil, foi tornado mais altivo (e talvez algo autoritário) por conta de seu nascimento nobre e pela reverência com que seu guardião a trata (não por acaso, ao fim do livro, o narrador informa que Ivanhoe ocasionalmente pensa em Rebecca de modo que Rowena não aprovaria).

Gurth e Wamba, um cuidador de porcos e um bobo, escapam, em um dado momento, aos papéis de meros serviçais, atuando de maneira bastante valorosa para garantir que os vilóes sejam derrotados. Cedric, pai de Ivanhoe e guardião de Rowena, é tão fervoroso no que diz respeito a suas origens saxãs, que faz praticamente todas as vontades de sua protegida por ela ser a última descendente de Alfred, o Grande. Além disso, sua determinação de assegurar o retorno de uma linhagem legitimamente saxã ao trono da Inglaterra faz com que ele se esforce sobremaneira para garantir um casamento entre Rowena e Athelstane, descendente de Edward, o Confessor. Em função disso, Cedric chega a rejeitar seu filho por este ser apaixonado por Rowena, além de ter adquirido certas maneiras normandas, notadamente no que diz respeito aos ideais de cavalaria.

Não apenas as personagens, mas os próprios eventos da narrativa fazem com que seja difícil considerar que Ivanhoe se enquadra sem mais no que se poderia considerar certos lugares-comuns de romances de cavalaria. Observe-se, por exemplo, que Wilfred, após ter sido gravemente ferido em um torneio que acontece em momento não tão distante do início da história, passa parte considerável da obra se recuperando, de modo que apenas volta à ativa para se envolver no conflito final com o vilão Bois-Gilbert. No que diz respeito aos confrontos entre eles, aliás, mais uma convenção é desobedecida: em vez de perder as primeiras lutas para triunfar na última (de maneira que poderia ser considerada, por assim dizer, catártica), Wilfred derrota Bois-Gilbert nos dois primeiros embates entre eles (o primeiro é apenas mencionado, já que ocorre em momento anterior ao início da narrativa) e, no último, tem uma vitória, por assim dizer, atípica: Ivanhoe, que ainda não está completamente recuperado de seu ferimento e mal consegue se manter na sela de seu cavalo, não chega a atingir Bois-Gilbert com sua lança. $O$ narrador informa que o malfeitor, intocado pela lança de seu inimigo, morrera por não suportar suas próprias paixões conflituosas. ${ }^{4}$

4 Sroka (1979) apresenta, em um artigo intitulado "The Function of Form: Ivanhoe as Romance”, um tratamento mais detalhado dos vários aspectos segundo os quais essa obra se distancia das convenções dos romances de aventuras, além de considerações interessantes sobre várias metáforas empregadas por Scott ao longo do livro. Entretanto, Sroka está interessado em mostrar em que medida aspectos da forma novela se apresentam ao longo de Ivanhoe, procurando mostrar em que medida isso colabora para a compreensão dos conflitos, no âmbito da obra, entre normandos e saxões. Essa abordagem, é claro, 
Existe um outro motivo para se considerar que o autor não pretendia que Ivanhoe fosse apenas um romance para entreter garotos sonhadores. Já na Epístola Dedicatória, temos indícios de que as intenções do autor eram consideravelmente mais ambiciosas. Ainda que essa carta tenha sido escrita por uma personagem fictícia (como, aliás, todo o livro), não há motivos pelos quais não se deva levar a sério algumas das considerações que ela traz acerca dos propósitos da obra. Desse modo, é importante não perder de vista passagens em que o autor manifesta estranhamento por conta da escassez de tentativas de despertar interesse pelos costumes antigos da Inglaterra, diferentemente do que se passava na Escócia do próprio Scott, o qual observa, ainda:

$\mathrm{O}$ verde de Kendal, ainda que seja mais antigo, deve certamente ser tão caro para nossos sentimentos quanto os tartãs multicoloridos do Norte. O nome de Robin Hood, quando devidamente conjurado, deve elevar o espírito tanto quanto o de Rob Roy. E os patriotas da Inglaterra não merecem menos renome em nossos círculos modernos que os Bruces e os Wallaces da Caledônia.' (Scott 2005, p. 25)

Não se trata, portanto, apenas de contar uma boa história. O que Scott pretende é contribuir para a restauração de uma certa memória que deveria ser cara por dizer respeito à própria fundação do que se poderia denominar a identidade nacional inglesa. Trata-se de uma tarefa que é apresentada como sendo bastante difícil, já que, diferentemente do que acontecia com os escoceses, os ingleses já não mostravam o mesmo interesse pelas figuras históricas que figurarão ao longo da obra. Esse, aliás, é o motivo pelo qual o autor se propõe a narrar os eventos de Ivanhoe em linguagem distintamente moderna. Além disso, esse fator constitui parte da justificativa para que o autor não seja tão rigoroso quando se trata de maneiras e de instituições relativas à época que ele procura retratar. ${ }^{6}$ Remeter o leitor aos ideais apresentados ao longo da obra é então, em alguma medida, fazer com que ele se reconheça em uma concepção determinada do que é ser inglês.

Isso confere importância considerável ao fato de a Epístola ser escrita por uma personagem fictícia que, aliás, afirma ter encontrado os supostos materiais

difere bastante daquela empreendida aqui.

5 Todas as traduções de passagens dos textos originais são nossas.

6 Essas imprecisōes dizem respeito tanto a aspectos pontuais, como por exemplo o fato de os templários pretenderem queimar Rebecca em uma fogueira por feitiçaria (essa prática ainda não era disseminada à época do reinado de Ricardo I), quanto ao próprio estado de tensão entre normandos e saxôes que constitui o pano de fundo de que dependem os eventos do livro. 
históricos que embasam sua narrativa no gabinete de outra personagem fictícia. Se Templeton, apresentado como autor do livro, e Arthur Wardour, suposto guardião dos documentos, aparecem em The Antiquary, outra obra de Scott, parece inevitável buscar algo como um tema, que Ivanhoe compartilhe com outras das chamadas Waverly Novels do mesmo autor. Parece oportuna, então, a observação segundo a qual

Essas novelas se concentram no processo que leva a um meio termo. Elas lidam com a "evolução orgânica de estilos de vida em disputa" ao dramatizar o conflito entre forças políticas adversárias e sua futura síntese. [...] A síntese, para o leitor, deve envolver a modificação de seu presente por sua compreensão e assimilação de seu passado. (Sroka 1979, p. 659)

A mensagem, portanto, é clara: ainda que se possa dizer que Ivanhoe e Ricardo I, que parecem ser os grandes heróis da história, sejam repletos de defeitos, são apresentados pelo autor como as personagens que, ao emergirem triunfantes dos conflitos que ocorrem ao longo da obra, indicam uma nova ordem a que a Inglaterra, então, será conduzida. Não causa estranhamento, portanto, que sejam retratados como exemplos de boa convivência entre normandos e saxões. Ivanhoe, como já foi dito, abraça as maneiras e os valores da cavalaria, tipicamente normandos, apesar de ser filho de um saxão que conspira para conduzir de volta ao trono a linhagem de Alfred.

Ricardo, por sua vez, é um rei normando, mas parece não apenas aceitar as maneiras saxãs, mas portar-se de modo a conquistar o respeito daqueles que aderem a elas. Isso fica evidente quando Cedric, em jantar oferecido pelo príncipe João, menciona o Coração de Leão como exemplo de normando a quem não faria ressalvas. O bando de Robin Hood, apresentado por Scott como paradigmático no que diz respeito a estabelecer um modelo do que seriam saxões valorosos, também parece ter grande respeito pelo rei. Ainda que este seja visto por Ivanhoe (com boas razōes) como alguém cujo amor por batalhas o impede, com frequência, de zelar como deveria por seu povo, fica claro que Ricardo tem qualidades que o tornam simpático aos saxões. Se não é possível defender que isso basta para que ele reine bem, ou para validar a sua adesão ferrenha aos códigos da cavalaria (a qual, como veremos, é censurada por Scott), ao menos confirma que, como já foi dito, o caráter que o autor pretende impingir à Inglaterra depende da fusão entre certos aspectos normandos e outros que são apresentados como saxões.

Se a ideia é promover essa conciliação, mostrando o modo pelo qual a combinação delas deveria levar ao estabelecimento da identidade nacional inglesa, há um desequilíbrio que causa estranhamento. Ainda que os saxões mereçam do 
autor algumas reprimendas, como por exemplo as que se referem ao fato de serem supersticiosos, eles parecem, de maneira geral, ser generosos, leais e, quando seus preconceitos não operam, justos. Mesmo Cedric, que não é uma personagem exatamente amistosa, recebe, no início da obra, um judeu e um peregrino em sua casa. Robin Hood e Frei Tuck são apresentados como hospitaleiros. O primeiro, ainda que seja tratado como um rei por seu bando, divide a pilhagem entre seus homens de maneira perfeitamente equânime. É verdade que, no Capítulo 40, Wamba faz comentários jocosos acerca dos procedimentos desses ladrões, mas não se trata de uma observação que pretende ser o juízo final do autor sobre eles, além de ser um caso que deve ser pesado contra o caráter geral que lhes é atribuído pelo autor.

Os normandos, por sua vez, são todos, à exceção de Ricardo, vilóes. O príncipe João conspira para retirar seu próprio irmão do trono. $\mathrm{O}$ barão de Bracy sequestra a comitiva de Rowena para forçá-la a se casar com ele. Front de Boeuf, outro barão normando, compraz-se com a perspectiva de torturar o judeu Isaac. Bois-Gilbert, cavaleiro templário de origem normanda, sequestra Rebecca, filha de Isaac, além de ser o principal antagonista do herói da história. Chama a atenção, ainda, que todos eles, à exceção (ocasional) do barão de Bracy, evidenciem completo desprezo por seus deveres enquanto nobres e pela religião que fingem observar. Contudo, isso não quer dizer que bastaria, para que os nobres normandos fossem modelos de caracteres desejáveis, que fossem menos hipócritas ao observar códigos de cavalaria. Ricardo, afinal, é apresentado pelo autor como sendo o melhor exemplo do

Caráter brilhante, porém inútil, de um cavaleiro de romance [...]. A glória pessoal que ele adquiriu por seus próprios feitos de armas era muito mais cara à sua imaginação excitável do aquela que um curso de boa política e sabedoria teria disseminado por seu reino. [...] Suas conquistas de cavalaria forneceram temas para bardos e menestréis, mas não conferiram a seu país nenhum daqueles benefícios sólidos em que a história adora se deter, e toma como um exemplo para a posteridade. (Scott 1993, p. 256)

Não se trata, portanto, de elogiar os ideais da cavalaria, mas de limitá-los pelo apreço àquilo que de fato traria benefícios ao povo. Não é por acaso, então, que Rebecca faz um elogio à paz da vida familiar, partindo daí para uma crítica do conceito de honra defendido por Ivanhoe. Os ideais da cavalaria, aliás, são apresentados em luz ainda mais desvantajosa quando os comparamos com os homens valorosos do bando de Robin Hood e, em alguma medida, também com 
a lealdade com que Gurth e Wamba, tipos completamente populares, entregam-se não apenas ao serviço de seus senhores, mas àquilo que suas convicções apontam como sendo correto. Os ideais da cavalaria, por si próprios, resultarão, na melhor das hipóteses, em boas letras de canções populares, o que parece muito pouco, já que também podem ser empregados para justificar os ardis de um de Bracy ou a violência de um Front de Boeuf. Pode-se dizer, então, que Ricardo teria como qualidades redentoras (e, no contexto da obra, tipicamente saxâs) sua franqueza, relativamente desprovida de adornos, e sua coragem galante, se vista como natural. Ocorre, porém, que essas características são mostradas em Ivanhoe como independentes dos ideais de cavalaria. A adesão cega a eles, no fim das contas, parece incompatível tanto com a boa política quanto com as maneiras que poderiam conduzir à felicidade privada. Desse modo, a conciliação deve ser entre as instituições normandas, que não são postas em questão, e as maneiras saxãs, mais rústicas e francas, que determinarão o modo como a sociabilidade deverá se estruturar. Nesse sentido, parece que Scott procura se distanciar de uma concepção acerca dos elos entre a galanteria dos cavaleiros e a polidez moderna que, se é desenvolvida por uma série de autores ao longo do século anterior, remonta, em grande medida, a David Hume. ${ }^{7}$ Parece oportuno, então, que nos detenhamos sobre o que o filósofo tem a dizer a esse respeito.

\section{II}

Hume, como se sabe, interessou-se precocemente pelo tema da cavalaria, tendo escrito, antes mesmo de publicar o Tratado da Natureza Humana, um curto ensaio sobre o tema, intitulado "An Historical Essay on Chivalry and Modern Honour". Nele, o filósofo, prenunciando a possibilidade de uma ciência do homem nos moldes da que seria desenvolvida no Tratado, apresenta consideraçóes segundo as quais o fenômeno da cavalaria teria sido o resultado inevitável de certas características da natureza humana. A cavalaria, entendida como fenômeno histórico, teria resultado de uma tentativa malfadada de apropriação, por parte dos povos bárbaros, de certas características que eles observaram nos romanos. Por ter sido desenvolvida por povos que não teriam o mesmo tipo de experiência que resultara na civilidade romana, a tradição da cavalaria resultara em um mundo "habitado por seres diferentes e regulado por leis diferentes" (Hume 1947, p. 57). Para os

7 Seguimos, a esse respeito, a sugestão de Ryu Susato (2006), para quem a posição de Hume merece ser observada tanto por conta do interesse precoce do pensador escocês sobre o tema da cavalaria quanto porque suas posiçóes sobre o tema parecem ter dado o tom do modo como ele seria tratado por outros autores escoceses do período, a exemplo de Kames e Robertson. 
"novos modernos", tratava-se de associar a aparência de cortesia e humanidade até mesmo ao combate, de modo que bons cavaleiros deveriam chegar a sorrir para aqueles cujas gargantas cortariam em seguida. Tendo essa tradição se espalhado, ela teria colaborado para introduzir, também, "a galanteria, e uma adoração pelo sexo feminino" (Hume 1947, p. 60). Essa devoção às mulheres é apresentada, no ensaio de juventude, de maneira bastante caricata: os mesmos cavaleiros que correm à procura de monstros e gigantes para combater sempre tratam as mulheres de maneira excessivamente servil. De qualquer modo, já era possível antever, em "Of Chivalry", uma tese que seria retomada posteriormente por Hume, ainda que em termos valorativos bastante distintos: a tradição da cavalaria, ao fomentar o surgimento de heróis que se destacariam pelo combate, mas se dedicariam às mulheres do mesmo modo que devotos se dedicam à divindade, teria engendrado tanto a galanteria quanto a prática de combate individual.

Esse, como se sabe, é um aspecto que Hume parece ainda considerar importante anos depois, ao escrever a seguinte passagem do Apêndice II de sua História da Inglaterra:

Essas ideias de cavalaria infectaram os escritos, a conversação e o comportamento dos homens por algumas eras, e, mesmo após terem sido, em grande medida, banidas pelo renascer da erudição, legaram aos modernos a galanteria e a questão de honra, que ainda mantêm sua influência, e são as crias genuínas dessas afetações antigas. (Hume 1985, p. 487)

No que diz respeito à questão de honra, cabem alguns esclarecimentos: a referência é, claramente, aos duelos. Isso fica explícito em um trecho do ensaio intitulado "Of the Rise and Progress of the Arts and Sciences" que foi suprimido na edição de I770, no qual Hume afirma que "O ponto de honra, ou prática de duelos, é uma invenção moderna, bem como a galanteria" (Hume I985, p. 628). A mesma passagem também deixa claro que essa prática seria perniciosa na medida em que, separando-se honra e virtude,

[...] os maiores devassos têm algo de que se gabar, e têm podido manter uma fachada respeitável, ainda que culpados dos maiores e mais vergonhosos vícios. Eles são depravados, gastões e nunca pagam nada do que devem, mas são homens de honra, e, portanto, devem ser recebidos como cavalheiros" (Hume i985, p. 626).

Além disso, o Apêndice II da História da Inglaterra permite entrever relações entre a questão de honra e os julgamentos por combate, que Hume denomina "um novo absurdo", o qual é associado à tradição da cavalaria, levada à Inglaterra 
pelos conquistadores normandos. (Hume 1985, p. 487)

Se a prática de duelos parece inequivocamente indefensável, o mesmo não pode ser dito da galanteria. É verdade que, no ensaio de juventude, Hume se refere a ela em termos não necessariamente elogiosos, falando em "adoração" pelo sexo feminino. É verdade, também, que a passagem da História da Inglaterra mencionada há pouco apresenta a galanteria como resultado da tradição que "infectava" escritos, pensamentos e conversas, e que foi "banida" pelo avanço da erudição. Ainda assim, diferentemente do que poderia ser dito com relação a duelos, a galanteria é importante não apenas por ainda gozar de prestígio, mas porque constitui um aspecto das tradições de cavalaria que Hume considera como tendo sido responsável, ao menos em alguma medida, pelo estabelecimento da polidez moderna. Isso fica bastante claro no já mencionado "Of the Rise and Progress of the Arts and Sciences". Nesse texto, o filósofo nos informa que

Se a superioridade, no que diz respeito à polidez, deve ser atribuída aos tempos modernos, as noçóes modernas de galanteria, que são o produto natural de cortes e monarquias, devem provavelmente ser consideradas as causas desse refinamento. Ninguém nega que essa invenção seja moderna. (Hume i985, p. I3I)

Alguns autores, como bem lembra Hume, poderiam afirmar que a galanteria é afetada ao ponto de se tornar ridícula, vendo-a como algo que poderia fazer com que recaísse descrédito sobre épocas mais modernas. É por isso que ele trata de empreender, em seguida, algo como uma defesa dessa prática. Segundo ele, a galanteria não pressupõe grande afetação, sendo, na verdade, um resultado bastante natural da afeição entre os sexos. Além disso, é também nesse hábito que tem suas raízes nas tradições de cavalaria que estaria embasada a fundação das boas maneiras, as quais tornam mais agradáveis a conversação e o intercâmbio de mentes (Hume 1985). Seria um traço distintivo do homem polido a capacidade de se portar com deferência diante de seus companheiros, além de afastar desconfianças infundadas por meio de um estudo que permita ver características alheias que poderiam dirimir impressões como essas. Ainda, as boas maneiras fariam com que alguém que foi educado de acordo com elas atente "para as necessidades de todos, esforçando-se para agradar tanto quanto é possível sem trair uma afetação visível demais" (Hume 1985, p. I32). É compreensível, então, que um homem civilizado entenda que, dada sua superioridade natural sobre as mulheres no que diz respeito à força física, ele mostre sua autoridade "de maneira mais generosa, ainda que não menos evidente: pela civilidade, pelo respeito, pela afabilidade e, em uma palavra, pela galanteria" (Hume 1985, p. 133). 
Além disso, segundo Hume, a galanteria não é, de maneira alguma, incompatível com a sabedoria e a prudência e, quando bem regulada, pode ser não apenas bom entretenimento, mas uma forma de melhorar o caráter dos jovens. Isso não apenas porque a mera satisfação dos apetites corporais não basta para contentar a mente, mas porque a companhia de mulheres virtuosas comunicaria aos admiradores delas um pouco de delicadeza e de modéstia, além de ensiná-los a tomar cuidado para evitar ofensas, polindo assim, insensivelmente, a sua linguagem, e tornando-a mais refinada e mais precisa (Hume 1985). Percebe-se, então, que, ainda que a galanteria, em seus particulares, seja resultado de uma apropriação que, por estar distante da experiência, é absolutamente fantasiosa, decorre, em igual medida, de inclinaçôes bastante naturais, e enseja que estas sejam refinadas de maneira que Hume considera inequivocamente benéfica. Fica evidente, portanto, não apenas que a galanteria é causa direta da polidez moderna, mas também que as maneiras modernas são um resultado que, em retrospecto, parece ter sido bastante louvável. Longe de ser uma mera excentricidade ou relíquia, é o que poderíamos chamar de ganho civilizatório.

É importante notar que não é apenas a tradição da cavalaria que, segundo Hume contribui para o estabelecimento da polidez. O ensaio que vem sendo mencionado traz, a esse respeito, uma outra consideração importante:

Em uma monarquia civilizada, há uma longa cadeia de dependência do príncipe até o camponês, que não é grande o suficiente para tornar a propriedade precária, ou deprimir as mentes das pessoas, mas basta para engendrar em cada um uma inclinação para agradar a seus superiores, e a se formar segundo modelos tais que sejam os mais aceitáveis a pessoas de boa condição e educação. A polidez de maneiras, portanto, surge muito naturalmente em monarquias e em cortes. (Hume 1985, p. I27)

É discutível que o reinado de Ricardo I fosse considerado por Hume já como uma monarquia civilizada, mesmo que, como fica claro no Apêndice II da História da Inglaterra, Hume considere a constituição normanda como o marco inicial do que se tornaria a civilização inglesa. É verdade que, no Apêndice, o desenvolvimento do feudalismo é apresentado de maneira compatível com a passagem acima. Entretanto, o engendramento da civilização é um processo que, no século XII, estaria, ainda, em curso. Isso fica evidente, por exemplo, quando Hume descreve os levantes contra judeus, que não teriam sido punidos porque “a culpa envolvia tantos dos cidadãos mais consideráveis", e que são relatados por um compilador que "louva o Todo-Poderoso por entregar [...] essa raça ímpia à destruição" (Hume i983, p. 379). Além disso, ao relatar a trégua estabelecida 
entre Ricardo i e Saladino, Hume não deixa de notar que "A vantagem, de fato, em ciência, em moderação, em humanidade estava, naquela época, inteiramente do lado dos sarracenos" (Ibid., p. 393). Observe-se, ainda, que Ricardo, mais preocupado em atingir a glória militar do que em estabelecer políticas firmes que garantissem a estabilidade do reino, toma decisóes equivocadas para o andamento do governo ao longo de sua ausência, as quais expõem a Inglaterra ao autoritarismo de Longchamp e a maquinaçōes por parte do rei da França.

É verdade que, se a passagem de "Of the Rise and Progress of the Arts and Sciences" mencionada há pouco termina com a consideração de que, em um estado como o descrito ali, nenhuma das artes liberais será negligenciada ou desprezada, o Apêndice II da História da Inglaterra deixa bastante claro que os baróes, vivendo de maneira opulenta, mas rústica, não encorajavam as artes. Entretanto, a descrição que o Apêndice apresenta das instituições feudais que os normandos haviam introduzido mostra claramente que os barões em situação mais elevada não podiam perder de vista sua dependência da boa vontade do rei e, os barôes menos importantes dependiam mais ainda dos mais elevados e, dentro de cada feudo, os habitantes dependiam de seus senhores. Assim, ainda que não houvesse atenção particular às artes liberais, certamente é possível supor que o feudalismo, tal como se manifestava à época, proporcionaria essa necessidade de agradar que teria como resultado, séculos mais tarde, parte expressiva da sociabilidade moderna. Fica estabelecido, desse modo, um vínculo bastante estreito entre a cavalaria, acolhida pela nobreza feudal, e a polidez elogiada por Hume. ${ }^{8}$

\section{III}

Já devem estar evidentes, a esta altura, as diferenças marcantes entre os modos como Hume e Scott veem os ideais da cavalaria que, para ambos, parecem ser uma característica importante do medievo. O filósofo, é claro, vê nas histórias de cavaleiros algo que decorre de uma imaginação fantasiosa, e compreende que elas acarretaram uma série de pequenos desastres, como o "ponto de honra". De qualquer modo, reconhece que, ao introduzir essa tradição, juntamente com o

8 Pode parecer estranho que o desejo de glória em combate, que é parte integrante da tradição de cavalaria, não tenha sido prejudicado pelo desenvolvimento da polidez. Hume oferece uma explicação para isso em outro ensaio, a saber, "Of Refinement in the Arts". Segundo o autor, a polidez, ainda que contribua para extinguir a raiva a partir da qual a coragem naturalmente surge, engendra, por outro lado, um senso de honra, além de permitir que soldados se portem com disciplina e com habilidade marcial que não seriam possíveis a um povo bárbaro. Tolonen (20I4) parte dessa tese para propor que o tratamento que Hume faz das noçóes de honra e coragem ecoa aquele proposto por Mandeville em seu Essay into the origin of honour, and the usefulness of Christianity in war. 
feudalismo, na Inglaterra, os normandos colaboraram para a disseminação do que seria, à época, um primeiro germe da polidez moderna, a qual é, para Hume, inequivocamente vantajosa.

Scott, por outro lado, parece ter pretendido que seu Ivanhoe se constituísse mais que uma crítica a costumes especificamente normandos, mas à própria tradição da cavalaria. Não é por conta de sua adesão a ela, afinal, que a personagem título se torna recomendável, mas justamente por perceber que ela precisaria ser limitada. Ricardo I, que é a figura que representa a concretização do cavaleiro ideal, deixa isso bastante claro: ainda que naturalmente capaz de granjear admiração, seu caráter, por mais que seja o de um homem justo, não é, de maneira alguma, o de um governante excelente ou o de alguém que, na convivência privada, seria considerado exemplar. ${ }^{9}$

Não se pode dizer, é claro, que não há quaisquer pontos de contato entre os dois autores. Scott é bastante cuidadoso, por exemplo, ao retratar de modo elogioso as habitações mais rústicas dos saxões, em contraponto ao tom desgostoso com que se refere aos excessos da decoração utilizada pelos normandos. Hume, do mesmo modo, observa, em seu "Essay on Chivalry", que parte das apropriações fantasiosas que resultaram na tradição da cavalaria consistia justamente em um excesso condenável de ornamentos na arquitetura, o qual resultava da má compreensão do que conferiria grandiosidade às construçôes romanas. Ainda assim, mesmo em pontos como esses não há concordância total: a simpatia de Hume não é pela rusticidade saxã, mas pela simplicidade elegante e grandiosa dos romanos, a qual não se pode mais recuperar. Ao se referir, em termos gerais, ao modo como era conduzida a política saxã, Hume não se furta a observar que ela não se organizava propriamente segundo Estados, mas na forma de sociedades que se reuniam em torno de guerreiros que fossem considerados particularmente proeminentes. As maneiras saxãs, do mesmo modo, passam longe de serem objeto de elogios efusivos.

Scott, por sua vez, também não pretende empreender apenas um elogio das maneiras saxãs. Ocorre, porém, que ele vê nelas um contraponto importante a um modelo que, para ele, seria impróprio tanto para organizar o Estado quanto a sociabilidade comum. É importante observar que, tendo escrito ensaios sobre a cavalaria e uma série de romances que lidavam com esse tema, e tendo se dedicado a isso pouco tempo depois de um debate em que a figura de Hume obtivera certa proeminência, Scott certamente estava consciente do que significaria recusar de

9 Nesse sentido, ganha peso a afirmação, por parte de Joseph Duncan (I955), de que Ivanhoe seria uma obra que se opõe ao chauvinismo, à cavalaria e ao romantismo. 
maneira taxativa os ideais da cavalaria. Quando Rebecca mostra a Ivanhoe que sua honra não o faria mais feliz que a simples felicidade doméstica, e quando o próprio narrador mostra que Ricardo não constituiria um exemplo de governante, o que fica claro não é apenas que cavaleiros não servem para governar, e talvez não sejam tão melhores no que diz respeito à vida cotidiana. Trata-se de uma tomada de posição, por parte do autor, em um debate bem determinado que dizia respeito não só à superioridade dos antigos ou dos modernos, mas também a que ideais a Inglaterra deveria buscar preservar.

Nesse sentido, ainda que os saxões não fossem, por si só, um exemplo de identidade a ser perseguida, certamente teriam colaborado mais do que os ideais da cavalaria com a constituição das maneiras inglesas. Diferentemente de Hume, que parece ver nos ideais trazidos pelos normandos a origem de práticas modernas que seriam superiores, Scott pretende recuperar, em alguma medida, certos ideais de rusticidade e common sense que, para ele, mereceriam mais crédito do que parecem ter recebido pelos defensores da polidez moderna. Não se trata, é claro, de promover um retorno à antiguidade (aliás, o que está em questão é recuperar ideais que não são propriamente clássicos). O que está em questão é mostrar que, no período em que terminou por se constituir, a nação inglesa deveu mais a uma fusão entre mundos distintos do que os defensores da galanteria teriam permitido ver. ${ }^{10}$ Torna-se, então, bastante explícito que Ivanhoe expressa inquietaçōes importantes, por parte de Scott, acerca do ideal de polidez que, elogiado por Hume, teria tido enorme importância para boa parte da filosofia britânica do século XviII. Não se deve perder de vista que o elogio de Hume a certo ideal de polidez implica, em alguma medida, a prescrição de certas maneiras. Mais do que apenas recomendar que a Inglaterra recupere algo da rusticidade saxã, o que Scott pretende é um acerto de contas com o próprio modelo de sociabilidade decorrente da conquista normanda e associado à cavalaria.

Esse é um aspecto interessante, já que, ainda no século XviII, esse modelo de polidez já vinha sendo recusado em mais de uma frente. Novelistas mulheres, é importante lembrar, puseram-se a escrever motivadas, em parte, pelo fato de seus

Io Não se deve pensar que o modelo proposto por Scott é visto pelo autor como isento de problemas: ao fim do livro, Rebecca diz a Rowena que irá viver na Espanha com seu pai, já que a Inglaterra, de qualquer modo, é um país violento, em que judeus não teriam qualquer segurança. Talvez isso queira dizer apenas que, em Ivanhoe, nada transcorre de maneira exatamente ideal. É possível, também, que haja aí uma denúncia, segundo a qual o autor empreenderia a crítica segundo a qual nem mesmo a passagem à nova ordem simbolizada pelo casamento de Ivanhoe e Rowena teria sido capaz de interromper as perseguições sofridas pelos judeus, as quais Scott, como Hume, deixa claro que não considera justas. 
apelos não terem muito espaço entre os escritores considerados sérios. De início, é verdade, concentraram-se em enredos que talvez pudessem ser considerados excessivamente sentimentais, mas que já indicavam que havia registros importantes para elas que não vinham recebendo a devida atenção. $O$ desenvolvimento das obras literárias tipicamente femininas abriu caminho, posteriormente, para sátiras como as de Charlotte Lennox e para análises sociais mais sofisticadas, como as de Jane Austen. Novelistas do sexo masculino, aliás, também já mostravam, em diversos casos, certa recusa do ideal de polidez que usualmente é associado à filosofia das luzes britânicas. O resgate de certa concepção do medievo que se vê, por exemplo, em diversas gothic novels, sejam elas escritas por homens ou por mulheres, deixa isso claro, o que ocorre, ao menos em parte, também por apelos a sentimentos exacerbados. ${ }^{\text {II }}$

Parece, então, que, como uma série de autores (ou de movimentos) que teriam surgido já a partir do século xviII, Scott pretende empreender uma recusa contundente de certa concepção de polidez que se teria tornado bem aceita. Entretanto, ele constitui um caso bastante particular. Ora, sua recusa da maneira de sociabilidade que ele associa à conquista normanda não se dá em favor da sensibilidade. Além disso, evidentemente, seu resgate do medievo não se dá como forma de justificar recursos ao sobrenatural, nem para favorecer uma atmosfera de mistério ou de obscuridade, como ocorre frequentemente na ficção gótica. Ainda que Ivanhoe seja um romance, o que está em questão é a crítica da polidez de origem normanda (e, com ela, de certa concepção da identidade nacional inglesa) por meio de um ataque ao próprio modo como a história colaborou para engendrá-la. Se considerarmos que a defesa dessa polidez empreendida por Hume, mas também por outros filósofos das luzes britânicas, associa-se a uma explicação histórica acerca de sua origem, a crítica de Scott se torna, ao fim e ao cabo, bastante incisiva.

\section{Referências bibliográficas}

Duncan, Joseph E. "The Anti-Romantic in 'Ivanhoe'. In: Nineteenth-Century Fiction. v. 9, n. 4 (1955), pp. 293-300.

Hume, David. Essays Moral, Political and Literary. Indianapolis: Liberty Fund, 1985.

"An Historical Essay on Chivalry and Modern Honour". Incluído em Mossner, Ernest Campbell. "David Hume's 'An Historical Essay on Chivalry and Modern Honour'”. In: Modern Philology. v. 45, n. I (1947), pp. 54-60.

II Ver, a esse respeito, Vasconcelos (2002). 
. The History of England. Indianapolis: Liberty Fund, 1983.

Sсотт, Walter. Ivanhoe. Nova York: Barnes \& Noble, 2005.

SROKA, Kenneth M. "The Function of Form: Ivanhoe as Romance". In: Studies in English Literature, 1500-1900, v. 19, n. 4 (1979), pp. 645-660.

Susato, Ryu. "The Idea of Chivalry in the Scottish Enlightenment: The Case of David Hume". In: Hume Studies, v. 33, n. I (2006), pp. 155-178.

Tolonen, Mikko. "The Gothic Origin of Modern Civility: Mandeville and the Scots on Courage". In: Journal of Scottish Philosophy, v. I2, n. I (2014), pp. 5I-69.

Vasconcelos, Sandra Guardini. Dez Liçôes sobre o Romance Inglês do Século XVIII. São Paulo: Boitempo Editorial, 2002. 